\title{
Prostatik kalsifikasyonun alt üriner sistem yakınmalarına etkisi
}

\section{The impact of prostate calcification on lower urinary tract symptoms}

\author{
Eyüp Veli Küçük1, Ahmet Tahra², Ahmet Bindayı, Ümit Yıldırım4, Resul Sobay', Uğur Tolga Șen¹
}

\section{öz}

AMAÇ: Prostat kalsifikasyonunun alt üriner sistem yakınmalarına (AÜSY) olan etkisini değerlendirmeyi amaçladık.

GEREC ve YÖNTEMLER: 2010-2016 yılları arasında AÜSY nedeniyle üroloji polikliniğine başvuran hastalar retrospektif olarak değerlendirildi. Çalışmaya kalsifikasyonu olmayan 58 hasta, orta derecede kalsifikasyonu olan 63 hasta ve ileri derecede kalsifikasyonu olan 56 hasta olmak üzere toplam 177 hasta dahil edildi. Hastalar, daha önce tarif edildiği üzere hiç kalsifikasyonu olmayan, orta derecede kalsifikasyonu olan ( $<3 \mathrm{~mm}$ uzunluk ve $<3$ adet) ve ileri kalsifiye ( $\geq 3$ adet veya $\geq 3 \mathrm{~mm}$ uzunluk) olarak üç gruba ayrıldı. Hastalara uluslararası prostat semptom skoru (IPSS) doldurtuldu ve maksimum akıș hızları değerlendirildi. Sürekli değişkenler varyans analizi ile kategorik değişkenler ki-kare ile değerlendirildi. Korelasyon değerlendirmeleri lojistik regresyon analizi ile yapildı.

BULGULAR: Hastaların ortalama yaşı 56,5 olarak belirlendi. Prostatik kalsifikasyon yaş ile ilişkili iken prostat volümü ile PSA düzeyi arasında pozitif bir korelasyon saptanmadı ve vücut kitle indeksi (VKI) ile ilişkili bulunmadı. Yaşa göre düzeltilmiş olarak AÜSY ve Qmax değerinin prostatik kalsifikasyon derecesine göre değerlendirmesine göre; depolama, boşaltım ve total IPSS semptom skorları ile prostatik kalsifikasyon ilişkisiz bulundu. Maksimum akış hızı ile prostatik kalsifikasyon arasında ilişki bulunamadı.

SONUÇ: Prostatik kalsifikasyonun AÜSY şiddetinin değerlendirilmesinde belirleyici bir faktör olmadığı tespit edildi.

Anahtar Kelimeler: Prostat kalsifikasyonu, alt üriner sistem yakınmalar1, uluslararası prostat semptom skoru
${ }^{7}$ Sağlık Bilimleri Üniversitesi Tıp Fakültesi, Ümraniye Sağık Uygulama Araştırma Merkezi, Üroloji Anabilim Dalı, Istanbul

${ }^{2}$ Tuzla Devlet Hastanesi, Üroloji Kliniği, İstanbul

${ }^{3}$ Bahçeşehir Üniversitesi Tıp Fakültesi, Medikal Park Göztepe Hastanesi, Üroloji Anabilim Dalı, Istanbul

${ }^{4}$ Artvin Devlet Hastanesi, Üroloji Kliniği, İstanbul

Yazışma Adresi / Correspondence:

Uzm. Dr. Ahmet Tahra

Tuzla Devlet Hastanesi, İstanbul - Türkiye

Tel. $\quad+905464660346$

E-mail: ahmettahra@gmail.com

Gelis / Received: 26.11.2017

Kabul / Accepted: 05.12.2017

\section{ABSTRACT}

OBJECTIVE: We aimed to evaluate the effect of prostate calcification on lower urinary tract symptoms (LUTS).

MATERIAL and METHODS: Patients who applied to urology clinic due to lower urinary system symptoms between 2010-2016 were retrospectively evaluated. A total of 177 patients were enrolled to this study; 58 patients without calcification, 63 patients with mild calcification and 56 patients with moderate/marked calcification. We classified the patients into three groups; those with no calculi, with mild calcification ( $<3$ calcification, $<3 \mathrm{~mm}$ length) and with moderate/ marked calcification ( $\geq 3$ calcification, $\geq 3 \mathrm{~mm}$ length). Patients filled the International Prostate Symptom Score (IPSS) and their maximum flow rates ( $Q$ max) were assessed. Categorical variables were evaluated with chi-square by variance analysis of continuous variables. Correlation evaluations were done by logistic regression analysis.

RESULTS: The mean age was 56.5. Prostatic calcification was associated with age, but there was no positive correlation between prostate volume and PSA level, and no association with body mass index (BMI). Age adjusted analysis showed that; storage, voiding total IPSS were not correlated with calcification. As to IPSS, no relationship was found between maximum flow rate and prostatic calcification.

CONCLUSION: Prostatic calcification is not a determining factor in the assessment of LUTS severity.

Keywords: Prostate calcification, lower urinary tract symptoms, international prostate symptom score

\section{Gíriș}

Prostat kalsifikasyonu, genellikle alt üriner sistem yakınmaları ve benign prostat hiperplazisi olan hastalarda, transabdominal veya transrektal yol ile yapilan ultrasonografi yardımı ile tespit edilmektedir. Başka bir yakınma ile (renal kolik vb.) yapılan direkt üriner sistem grafisi veya bilgisayarlı tomografi ile de prostatik kalsifikasyon varlığı gözlenmekte, ancak varlıkları çoğunlukla göz ardı edilmektedir. Kalsifikasyonun nedeni henüz net değildir. Yapılan klinik çalışmalarda, prostatik kanallarla idrar reflüsü, spermatozoanın kanallara penetrasyonu, prostat epitelinin kronik inflamasyona yanıtı ve kronik bakteriyel prostatit patofizyoloji de suçlanmaktadır. ${ }^{[1]}$ 
Yapılan klinik çalışmalardan, kalsifikasyonların AÜSY’ye yol açtığı bazı çalışmalarda ise prostat kanseri ile ilişkili olabileceği bildirilmektedir ama kanser ile ilişkisi halen net değildir. ${ }^{[2-5]}$ Yakın zamanda yapılan klinik çalışmalarda, prostatik kalsifikasyonun AÜSY’ye negatif etki yaptığ1 ortaya konulmuştur. ${ }^{[3,6]}$ Subjektif yakınmaların yanında, objektif değerlendirmelerde kalsifikasyonun akım hızını azalttığı bildirilmiştir. ${ }^{[3]}$ Güncel literatürde, periüretral fibrozis ve kalsifikasyonun AÜSY'nin etyolojisinde önemli rol oynadığı ve periüretral kalsifikasyonun AÜSY'yi arttırdığını bildiren çalışmalar mevcuttur. ${ }^{[7]}$

$\mathrm{Bu}$ klinik çalışmada, prostat kalsifikasyonu ve bunun alt üriner sistem yakınmalarına etkilerinin objektif ve subjektif olarak değerlendirilmesi amaçlanmaktadır.

\section{GEREÇ VE YÖNTEM}

2010 ile 2016 yılları arasında üroloji polikliniğine başvuran ve transrektal ultrasonografi (TRUS) ile poliklinik değerlendirmeyi kabul eden ve üroflovmetrik değerlendirme yapılan (Maksimum akış hızı ve Post miksiyonel rezidü) 45 yaş (ort: 56,5) üzeri erkek hastalar, retrospektif olarak bu çalışmaya dahil edildi. Çalışmaya, kalsifikasyonu olmayan 58 hasta, orta derecede kalsifikasyonu olan 63 hasta ve ileri derecede kalsifikasyonu olan 56 hasta olmak üzere toplam 177 hasta dahil edildi. Hastaların ayrıntılı öyküleri alındı. Fizik muayene öncesinde hastalara Uluslararası Prostat Semptom Skoru (IPSS) formu doldurtuldu. Hastaların vücut kitle indeksi (VKİ), PSA düzeyleri ve biyokimyasal değerleri retrospektif olarak kaydedildi.

Aktif üriner enfeksiyonu olan, mesane ve/veya prostat kanseri tanısı olan, hormon tedavisi alan, kontrolsüz diyabeti olan, AÜSY'ye yol açacak nörolojik hastalığı olan, pelvise radyoterapi alan hastalar çalışmaya dahil edilmedi. Seksen ve üzeri yaşı olan ve üroflovmetrik çalışmada maksimum akış hızı çok düşük ( $<5 \mathrm{~mL} / \mathrm{sn})$ olan hastalar çalışma dışında kabul edildi.
Hastalar, aynı USG cihazı ve aynı kişi tarafından değerlendirildi. Hastalar, daha önce tarif edildiği üzere, hiç kalsifikasyonu olmayan, orta derecede kalsifikasyonu olan ( $<3 \mathrm{~mm}$ uzunluk ve $<3$ adet) ve ileri kalsifiye ( $\geq 3$ adet veya $\geq 3 \mathrm{~mm}$ uzunluk) olarak üç gruba ayrildı. Semptom skoru (IPSS) ise hafif (0-7), orta (8-19) ve şiddetli (20-35) olarak değerlendirildi. Hastalara idrar akım testi yapıldı ve maksimum idrar akışı kaydedildi. Sürekli değişkenler varyans analizi ile, kategorik değişkenler ki-kare ile değerlendirildi. Korelasyon değerlendirmeleri lojistik regresyon analizi ile yapıldı. Tüm istatistiksel değerlendirme, SPSS versiyon 20 (SPSS, version 20.0.0.2, IBM Corp., Armonk, NY) programı aracılığı ile yapıldı. İstatistiksel anlamlılık olarak p değeri $<0,05$ olarak kabul edildi.

\section{BULGULAR}

Hastaların klinik ve demografik verileri Tablo 1'de özetlenmektedir. Prostatik kalsifikasyon yaş ile ilişkili iken, prostat volümü, PSA düzeyi ve VKİ ile ilişkili bulunmad. Hastaların ortalama yaş 56,5 olarak belirlendi. Hasta yaşı, kalsifikasyonu olmayan hastalarda $(n=58) 55,2 \pm 7,44$, orta derecede kalsifikasyonu $(\mathrm{n}=63) 55,4 \pm 6,56$, ileri derecede kalsifiye olan hastalarda $(n=56)$ ise $56,1 \pm 6,3$ olarak belirlendi.

Tablo 2'de, yaşa göre düzeltilmiş olarak, AÜSY ve Qmax değerinin prostatik kalsifikasyon derecesine göre değerlendirmesi mevcuttur. Depolama, boşaltım ve total IPSS semptom skorları ile prostatik kalsifikasyon ilişkisiz bulundu. Maksimum akış hızı ile prostatik kalsifikasyon arasında ilişki bulunamadı.

Tekli değişkenli analizlerde ise, şiddetli AÜSY ile prostatik kalsifikasyon derecesi, yaş, prostat volümü ve serum PSA düzeyleri incelenmiş ve bağımsız bir öngörücü olmadıkları tespit edilmiştir. Benzer şeklide yapılan çoklu değişkenli analizde, bu faktörlerin bağımsız bir öngörücü olmadığı gözlenmiştir.

Tablo 1. Prostat kalsifikasyonu derecesine göre demografik veriler

\begin{tabular}{lcccc} 
& $\begin{array}{c}\text { Kalsifikasyonu olmayan } \\
(n=58)\end{array}$ & $\begin{array}{c}\text { Orta derecede kalsifive } \\
(n=63)\end{array}$ & $\begin{array}{c}\text { ileri derecede kalsifiye } \\
(n=56)\end{array}$ & $P$ değeri \\
\hline Yaş (yıl) & $55,2 \pm 7,44$ & $55,4 \pm 6,56$ & $56,1 \pm 6,3$ & 0,04 \\
Prostat volümü $(\mathrm{mL})$ & $34,3 \pm 9,43$ & $35,1 \pm 8,32$ & $36,3 \pm 7,57$ & 0,18 \\
PSA (ng/ml) & $1,3 \pm 1,42$ & $1,34 \pm 1,36$ & $1,32 \pm 7,44$ & 0,66 \\
VKi $\left(\mathrm{kg} / \mathrm{m}^{2}\right)$ & $26,9 \pm 3,12$ & $26,8 \pm 3,31$ & $26,6 \pm 2,99$ & 0,54 \\
\hline
\end{tabular}

PSA: Prostat Spesifik Antijen, VKi: Vücut Kitle İndeksi 
Tablo 2. Yaşa göre düzeltilmiş AÜSY ile prostat kalsifikasyonu ilişkisi

\begin{tabular}{lcccc} 
& $\begin{array}{c}\text { Kalsifikasyonu olmayan } \\
(n=58)\end{array}$ & $\begin{array}{c}\text { Orta derecede kalsifiye } \\
(n=63)\end{array}$ & $\begin{array}{c}\text { ileri derecede kalsifiye } \\
(n=56)\end{array}$ & P değeri \\
\hline IPSS toplam & $14,83 \pm 5,78$ & $15,02 \pm 5,38$ & $15,11 \pm 5,03$ & 0,19 \\
Boşaltım semptomları & $7,73 \pm 2,36$ & $8,01 \pm 2,25$ & $8,12 \pm 2,58$ & 0,78 \\
Depolama semptomları & $7,1 \pm 3,42$ & $7,01 \pm 3,13$ & $6,99 \pm 2,55$ & 0,61 \\
Qmax (ml/s) & $16,87 \pm 8,86$ & $17,72 \pm 7,72$ & $17,16 \pm 6,98$ & 0,58 \\
\hline
\end{tabular}

IPSS: 'International Prostate Symptom Score' (Uluslararası Prostat Semptom Skoru)

\section{TARTIȘMA}

Prostatik kalsifikasyon özellikle BPH nedeni ile yapılan değerlendirmede tespit edilse de, klinik anlamı ve patofizyolojisi halen net değildir. Prevalans ile ilgili çalışmalarda, kalsifikasyonun tanımı ile ilgili problem mevcut olup \%7,3-71 civarında BPH ve/veya kronik prostatit ilişkisi bildirilmiştir. ${ }^{[2,5,8-10]}$ Prostatik kalsifikasyon ve/veya taşın etyolojisinde, prostatik sekresyonların corpora amylacea'da birikmesi suçlanmaktadır. Çoğunlukla, bu kalsifikasyonlarda inflamasyona sekonder lenfosit ve histiyosit infiltrasyonu gözlenmiştir. ${ }^{[2,5,11-13]}$

Literatürde prostatik kalsifikasyon ile AÜSY ve idrar akım hızı ilişkisini araştıran çalışmalar mevcuttur. Yaptığımız bu çalışmada, mevcut literatürün çoğunlukla uzlaşmaya vardığı bulguların aksine, prostatik kalsifikasyon ile AÜSY ve maksimum idrar akım hızının ilişkisi olmadığı görülmüştür.

Yang ve ark. tarafından yapılan ve 40 yaş ve üzeri, gönüllü olan toplam 604 hastanın değerlendirildiği bir çalışmada, prostatik kalsifikasyonun varlığı ve boyutunun, AÜSY'ye negatif etkide bulunduğu gözlenmiştir. ${ }^{[14]} \mathrm{Han}$ ve ark. tarafından yapılan diğer bir çalışmada, 1030 hasta periüretral ve prostatik kalsifikasyon açısından retrospektif olarak değerlendirilmiş, ortalama yaş $62,05 \pm 9,96$, ortalama IPSS $16,77 \pm 7,48$ olarak bulunmuş olup, prostatik ve periüretral kalsifikasyonun AÜSY'yi arttırdığı, idrar akım hızında azalmaya yol açtığı bildirilmiştir. ${ }^{[15]}$ Benzer şekilde yapılan başka bir çalışmada da, periüretral fibrozisin AÜSY etyolojisinde önemli bir rol oynadığı önerilmiştir. ${ }^{[7]}$

Park ve arkadaşlarının toplam 802 hastayı (355 prostat kalsifikasyonu olan hasta, 467 kalsifikasyonu olmayan hasta) inceledikleri bir çalışmada, ortalama yaşları 70,5 $\pm 10,7$ ila $64,8 \pm 12,8$ yil olan, ortalama IPSS skorları ise $15,7 \pm 9,2$ ila $14,1 \pm 9,1$ ve ortalama prostat volümleri $29,7 \pm 17,3$ ila 25,5 $\pm 16,5$ olan hasta gruplarında prostatik taşın AÜSY ile ilişkisi araştırılmış; tek değişkenli analizlerde, yaş, prostatik taş ve prostatit AÜSY şiddeti için bağımsız öngörücü faktörler olarak belirlenmiş olup, çoklu değişkenli analizlerde ise prostatik taşın oluşumunun yaş ve prostat boyutu ile ilişkili olabileceği, ancak prostatik taşın şiddetli AÜSY'nin şiddeti için bağımsız öngörücü faktör olmadığı gözlenmiştir. ${ }^{[3]}$ Kim ve ark. ise, benign prostat hiperplazisi nedeni ile transüretral rezeksiyon uyguladıkları ortalama yaşları $68,7 \pm 7,5$ yıl olan 225 hastanın, ortalama prostat volümü-

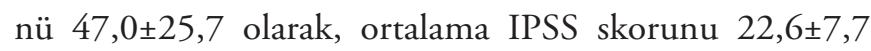
olarak belirlemişler; bu 225 hastayı retrospektif olarak değerlendirip, prostatik taşı tip A (ayrı küçük yansıma), tip B (büyük çoklu yansıma), tip $\mathrm{M}$ (her iki tip) ve tip $\mathrm{N}$ (taşsızlık) olarak gruplamışlar; gruplar arasında total IPSS, depolama IPSS ve boşaltım IPSS açısından, çalışmamıza benzer şekilde, fark bulamamışlardır. ${ }^{[2]}$ Park ve Choo tarafından yapılan diğer bir çalışmada, transrektal USG ile değerlendirilen 606 hasta çalışmaya alınmış (prostatik taş olmayan 142 hasta ve taşı olan 464 hasta), bunların ortalama yaşları $52,46 \pm 12,88$ ile $59,94 \pm 11,73$ yıl, ortalama prostat volümü $24,18 \pm 7,84$ ila $26,78 \pm 10,18$ olarak belirlenmiş olup, hasta grupları karşılaştırıldığında, prostatik taşın total IPSS, boşaltım IPSS ve QoL skorları ile korele olmadığı, ancak depolama semptomlarını şiddetlendirdiği ortaya konulmuştur. ${ }^{[16]}$ Ancak çalışmamızın aksine, Kim ve ark. tarafından yapılan diğer bir çalışmada, 40-59 yaş arası rutin kontrol yapılan, ortalama prostat volümü $24,5 \pm 7,1$ olan 1575 hasta değerlendirilmiş, prostatik taş olmayan ve küçük taşı olan grup ile büyük taşı olan grup olmak üzere iki gruba ayrılmış, taş büyüklüğünün orta ve şiddetli AÜSY için bağımsız bir öngörücü olduğu belirtilmiştir. ${ }^{[6]}$

Çalışmamızda, yaş ile prostatik taşın arttığı gözlenmiştir. Prostat taşlarının insidansının yaş ile arttığı, 40 yaş üzerinde genç yaşa göre daha çok sayıda ve büyük prostatik taş olduğu gösterilmiştir. ${ }^{[10,17]}$ Yapılan otopsi serisinde, $\geq 1 \mathrm{~mm}$ çaplı prostatik taşın yaş ile arttığı gösterilmiştir. ${ }^{[18]}$

Çalışmamızda, maksimum akış hızı ile prostatik kalsifikasyon ilişkisiz olarak bulunmuştur. Prostat kalsifikasyonunun AÜSY'ye etki ettiğini bildiren çalışmalarda, objektif bir yöntem ile ürodinamik parametreler genellikle değerlendirilmemiştir. Han ve ark. tarafından yapılan çalışmada, periüretral ve prostatik kalsifikasyonun maksimum idrar 
akışı ile istatistiksel bir ilişkisi olduğunu belirtilmekle birlikte, bu ilişkinin sayısal olarak çok az miktar olduğu bulunmuştur. ${ }^{[15]}$ Yang ve ark. ise, kalsifikasyon şiddeti arttıkça obstrüktif hasta (Q $\max <15 \mathrm{ml} / \mathrm{sn}$ ) oranında artış bildirmişlerdir. ${ }^{[14]}$

Metabolik sendrom, gün geçtikçe sayısı çoğalan çalışmalar ile birlikte, AÜSY'de etkisi araştırılan bir konudur. Yapılan çalışmalarda, gerek metabolik sendromun kendisinin gerekse komponentlerinin AÜSY’yi etkilediği gösterilmiştir. ${ }^{[19]}$ Ancak, vücut kitle indeksi ile prostatik kalsifikasyon arasında ilişki henüz netlik kazanmamıştır. Çalışmamızda VKİ'nin prostatik kalsifikasyon ile ilişkili olmadığı gösterilmiştir. Çalışmamıza benzer bir şekilde, Yang ve ark. tarafından yapılan çalışmada, metabolik sendrom ile prostatik kalsifikasyonun ilişkisinin olmadığı gösterilmiş olup, metabolik belirteçler ve serum biyokimyasal değerlerinin kalsifikasyonu olan ve olmayan gruplar arasında farklılık göstermediği bildirilmiştir. ${ }^{[14]}$

Çalışmamızın limitasyonları; hasta sayısının kısıtlı olması, hastaların yaşlarının çok ileri olmaması ve buna bağlı olarak yaş ile kalsifikasyonun ve AÜSY'de etkisinin net olarak değerlendirilememesi, eşlik eden komorbidite ve metabolik sendrom ile AÜSY ve prostatik kalsifikasyon ilişkisinin değerlendirilememesi, hasta sayısı ve dağılımına bağlı analizlerin kısıtlılığı ve retrospektif olarak yapılması sayılabilir. Literatürde, AÜSY ve prostatik kalsifikasyon için prospektif, tüm yaşlardan hastaların dahil olduğu, gerekli histopatolojik incelemelerin yapılabildiği çalışmalara ihtiyaç vardır.

\section{Hakem Değerlendirmesi}

Dış bağımsız

\section{Çıkar Çatışması}

Yazarlar çıkar ilişkisi olmadığını beyan etmişlerdir.

\section{Peer-review}

Externally peer-reviewed.

\section{Conflict of Interest}

No conflict of interest was declared by the authors.

\section{KAYNAKLAR}

1. Engelhardt PF, Seklehner S, Brustmann H, Riedl C, Lusuardi L. Tumor necrosis factor- $\alpha$ expression in patients with obstructive benign prostatic hyperplasia is associated with a higher incidence of asymptomatic inflammatory prostatitis NIH category IV and prostatic calcification. Scand J Urol 2015;10:1-7. doi: 10.3109/21681805.2015.1044560

2. Kim SH, Jung KI, Koh JS, Min KO, Cho SY, Kim HW. Lower urinary tract symptoms in benign prostatic hyperplasia patients: orchestrated by chronic prostatic inflammation and prostatic calculi? Urol Int 2013;90:144-9. doi: 10.1159/000342643

3. Park SW, Nam JK, Lee SD, Chung MK. Are prostatic calculi independent predictive factors of lower urinary tract symptoms?
Asian J Androl 2010;12:221-6. Urol Int 2013;90:144-9. doi: 10.1038/aja.2009.75

4. Hwang EC, Choi HS, Im CM, Jung SI, Kim SO, Kang TW, et al. Prostate calculi in cancer and BPH in a cohort of Korean men: presence of calculi did not. Androl 2010;12:215-20. doi: 10.1038/ aja.2009.86

5. Shoskes DA, Lee CT, Murphy D, Kefer J, Wood HM. Incidence and significance of prostatic stones in men with chronic prostatitis/ chronic pelvic pain syndrome. Urology 2007;70:235-8. doi: 10.1016/j.urology.2007.04.008

6. Kim WB, Doo SW, Yang WJ, Song YS. Influence of prostatic calculi on lower urinary tract symptoms in middle-aged men. Urology 2011;78:447-9. doi: 10.1016/j.urology.2010.12.056

7. Rodriguez-Nieves JA, Macoska JA. Prostatic fibrosis, lower urinary tract symptoms, and BPH. Nat Rev Urol 2013;10:546-50. doi: 10.1038/nrurol.2013.149

8. Harada K, Igari D, Tanahashi Y. Gray scale transrectal ultrasonography of the prostate. J Clin Ultrasound 1979;7:45-9.

9. Lee SE, Ku JH, Park HK, Jeong CK, Kim SH. Prostatic calculi do not influence the level of serum prostate specific antigen in men without clinically detectable prostate cancer or prostatitis. J Urol 2003;170:745-8. doi: 10.1097/01.ju.0000081650.23715.4c

10. Geramoutsos I, Gyftopoulos K, Perimenis P, Thanou V, Liagka $\mathrm{D}$, Siamblis D, et al. Clinical correlation of prostatic lithiasis with chronic pelvic pain syndromes in young adults. Eur Urol 2004;45:333-7. doi: 10.1016/j.eururo.2003.09.020

11. Ficarra V, Sekulovic S, Zattoni F, Zazzera M, Novara G. Why and how to evaluate chronic prostatic inflammation. Eur Urol Suppl 2013;12:110-5. doi: 10.1016/j.eursup.2013.08.002

12. Untergasser G, Madersbacher S, Berger P. Benign prostatic hyperplasia: age-related tissue-remodeling. Exp Gerontol 2005;40:121-8. doi: 10.1016/j.exger.2004.12.008

13. Bianchi-Frias D, Vakar-Lopez F, Coleman IM, Plymate SR, Reed MJ, Nelson PS. The effects of aging on the molecular and cellular composition of the prostate microenvironment. PLoS One 2010;1;5:e12501. doi: 10.1371/journal.pone.0012501

14. Yang HJ, Huang KH, Wang CW, Chang HC, Yang TK. Prostate calcification worsen lower urinary tract symptoms in middle-aged men. Urology 2013;81:1320-4. doi: 10.1016/j. urology.2013.02.021

15. Han JH, Kwon JK, Lee JY, Kang DH, Choi HC, Lee JS, et al. Is periurethral calcification associated with urinary flow rate and symptom severity in men with lower urinary tract symptomsbenign prostatic hyperplasia? A retrospective review. Urology 2015;85:1156-61. doi: 10.1016/j.urology.2015.01.038

16. Park B, Choo SH. The burden of prostatic calculi is more important than the presence. Asian J Androl 2017;19:482-5. doi: 10.4103/1008-682X.181193

17. Fox M. The natural history and significance of stone formation in the prostate gland. J Urol 1963;89:716-27.

18. Søndergaard G, Vetner M, Christensen PO. Prostatic calculi. Acta Pathol Microbiol Immunol Scand A 1987;95:141-5.

19. Park YW, Kim SB, Kwon H, Kang HC, Cho K, Lee KI, et al. The relationship between lower urinary tract symptoms/ benign prostatic hyperplasia and the number of components of metabolic syndrome. Urology 2013;82:674-9. doi: 10.1016/j. urology.2013.03.047 